\title{
Crítica científica de "A colaboração premiada como instrumento de política criminal" - Um adendo sobre a necessária visão político-criminal do processo penal
}

Scientific criticism to "the plea bargain as a criminal policy instrument" - one commentary about the essential criminal policy

vision of the criminal procedure

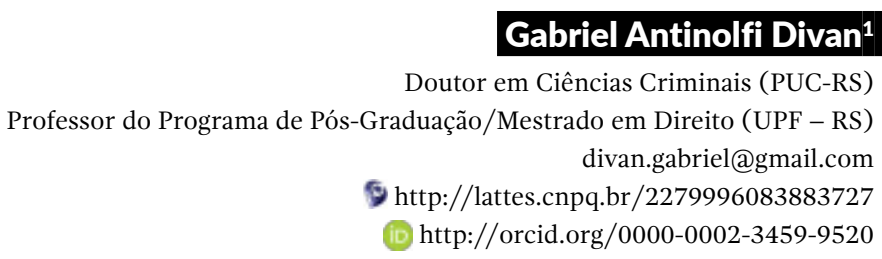

\section{INTRODUÇÃO}

No texto intitulado "A colaboração premiada como instrumento de política criminal: a tensão em relação às garantias fundamentais do réu colaborador", Aires e Fernandes trabalham a perspectiva de umas das discussões nucleares do debate político-criminal, a saber, a medida de equilíbrio entre uma teleologia de eficiência (e suas circunstâncias) e a sedimentação de garantias (e suas circunstâncias) frente ao sistema jurídico-penal.

1 Doutor e Mestre em Ciências Criminais pela Pontifícia Universidade Católica do Rio Grande do Sul. Pós-Graduado (Especialização) em Ciências Penais, pela mesma universidade. Atualmente exerce o cargo de Professor Adjunto da Universidade de Passo Fundo - RS (UPF), credenciado como professor do Programa de Pós Graduação da Faculdade de Direito - Mestrado. Lidera o Grupo de Pesquisa Reclame as Ruas: Direito, Política e Sociedade, certificado junto ao CNPq. Advogado e pesquisador. 
O pano de fundo, ou lente pela qual os autores se debruçam sobre a discussão é, oportunamente, um dos mais controversos e instigantes debates acadêmicos e mesmo forenses da atualidade, na seara: a estrutura legal, doutrinária e (sobretudo) política da 'colaboração premiada' - instituto revigorado no arcabouço legislativo pátrio pela Lei n. 12.850/2013, e instrumento de coleta informativa e probatória de destaque frente a uma série de desdobramentos do complexo investigativo/policial e processual/judiciário que emana da já notória “Operação Lava Jato" (que apura uma série vultuosa de fraudes envolvendo substancialmente lavagem de dinheiro, pagamento de 'propinas', financiamento eleitoral por recursos não contabilizados e fraudes licitatórias e contratuais envolvendo o poder público em várias esferas).

No âmbito da chamada "Lava Jato", o número de suspeitos, investigados, indiciados e réus ( $\mathrm{e}$, mesmo, de já condenados) que buscou amparo nas premissas legais da "colaboração premiada" para procurar atenuar os resultados penais e punitivos da persecução em vários níveis, contra si, chama a atenção - tanto quanto o número de homologações judiciais das propostas e sessões de depoimentos reiteradas e contínuas - que tornam esse tipo de expediente probatório o centro do debate jurídico-penal atual, e sumamente, tema de importância elevada para a discussão que entrecruza direito processual penal e política-criminal. Mais: inaugura um novo e incontornável exemplo e flanco de debate sobre as aspirações práticas e políticas dos institutos processuais penais em termos de resultados jurídicos e sociais eventualmente buscados ou atingidos.

Aqui, de pronto, percebe-se a tamanha importância da discussão e a felicidade dos autores em promover a reflexão em acertado prisma, e mesmo em abrir flancos de crítica que precisam encorpar os questionamentos em torno do tema.

Essa revisão crítica e analítica dos temas trazidos pelos autores no trabalho estudado procurará se focalizar com muito mais afinco nesse caráter de fundo, que informa e propõe limites e pertinências de conjecturas político-criminais no processo penal, do que em outros aspectos do desenvolvimento do texto, uma vez que se entende não como espécie de contraponto ou antagonismo ao mesmo em todas suas constatações, mas sim de reflexão inclusive dialogal ou iniciada a partir do mesmo. 


\section{Processo penal enquanto instrumento de política criminal - a TELEOLOGIA EM DISCUSSÃO}

Em nosso sentir, a abordagem relativa à consideração do processo penal como instrumento de política criminal precisa ser levada com cautela. Não se deve aceitar sem maiores questionamentos e restrições a ideia de que o processo penal possa (ou deva) ser utilizado como legítimo instrumento ou parte do sistema jurídico-penal à moda de ser caracterizado, muitas vezes, como um aparelho que simplesmente chancela ou coaduna com o poder punitivo estatal (ainda que no artigo seja - e de forma bem feita - explicitada a necessidade de se ponderar vetores de eficiência com aqueles de garantia, sobre o que falaremos infra).

Há muito tempo o debate sobre uma especulada função ou um papel político-criminal do processo penal e uma leitura assim condizente dos seus institutos legais e caracteres dogmáticos ganha tons pertinentes, na própria lição de Fernandes (2001, p. 47-48), que alerta:

Contra essa aproximação da justiça criminal à política geral, insurge-se com o argumento fundado na necessidade de uma neutralidade ideológico-política das entidades pertencentes ao foro judiciário, ou, por outras palavras, da necessidade de que a função de aplicação do Direito se mantenha distante das querelas do poder [...] Barreiros aponta o vício metodológico de que ela padece, consistente na 'indevida autonomização daquilo a que chama a política da lei relativamente à estrutura política tal qual ela resulta discutida e deliberada pelas instâncias soberanas do ordenamento constitucional', ideia essa que se funda no suporte teórico de que a Lei é suficiente para determinar os critérios de actuação da Justiça.

A proposta relativa a uma visão político-criminal do processo penal e seus standards já fora expressamente defendida em outra oportunidade, ao pugnar que sejam incorporadas à discussão e ao estudo dos institutos processuais as "intenções político-criminais que orientam o sistema jurídico penal como um todo" (FERNANDES, 2001, p. 54).

Em um primeiro momento, o tom desta crítica científica é de concordância com a referida premissa, uma vez que parece plausível e em tom acertado compatibilizar seu teor com outros ensinamentos e pontos 
seguros de análise: Cirino dos Santos (2002, p. 53) faz afirmação importante ao estabelecer as normas incriminadoras (fonte de Direito Penal material) são o centro gravitacional e principal da política criminal - o que coloca o debate básico do direito substancial não como única esfera político-criminal, mas, apenas, como a mais aguda. Com isso, podemos concordar: de fato, o problema da discussão político criminal se perfaz não tanto em considerar o debate primordial das normas incriminadoras como ponto de partida, e sim em estabelecer (ou resumir) a discussão político-criminal sem incluir o debate processual e mesmo teleológico.

Duas constatações que enriquecem a tese ora esboçada aqui:

A primeira diz para com o fato de que é cansativo perceber que muito do que se procura discutir em termos de política-criminal em nossa literatura especializada se resume a uma análise quase quantitativa e catalogar de variações de incriminações ou descriminalizações quanto a determinados temas-objeto de tutela penal, sem propriamente invadir a fronteira de uma genuína discussão sobre finalidades de ordem gerencial, política ou estratégica dos conceitos e instrumentos legislativos. É uma espécie de vício de "enfoque legiferante" que contamina e gerencia as especulações sobre o tema (DIVAN, 2015, p. 54-60).

A segunda informa que uma própria filtragem constitucional que leve em conta a série inafastável de propósitos que procuramos certa vez denominar de "índole constitucional" (Cf. DIVAN, 2012), e o próprio debate em torno das garantias processuais e sua interpretação conforme atinge necessariamente a constatação político-criminal e tangencia a ideia de ingerências sobre uma teleologia da aplicação do direito processual e das posturas científicas sobre o mesmo. Na esteira de Casara e Melchior (2014, p. 32), temos que:

A busca por um processo penal democrático passa pela compreensão de seu funcionamento como parte integrante do sistema de justiça criminal. Este entendimento, desdobramento natural da dimensão política do processo penal, modifica o olhar com que as categorias do processo penal devem ser concebidas. Como consequência, o estudo do processo penal deve ser realizado tendo em conta o impacto e influência recíproca que cada teoria, decisão, conduta ou dispositivo legal tem em relação a todos os restantes ramos que integram o sistema criminal. 
Nessa linha, Roxin (2000, p. 22) toma a problemática, já consolidada em termos de Direito Penal, como ponto de partida para elucubração sobre uma possibilidade de admissão funcional de todo o sistema (e poder-se-ia pensar aqui em um encaixe nada forçoso da esfera processual no diálogo).

Enfim: não faltam aportes e miradas para uma conclusão segura - em primeira análise - que, sim: o processo penal e o Direito Processual Penal, em sentido amplo, podem ser vistos como elementos que merecem inclusão numa pauta de debates político-criminais, no sentido de que a) compõem inegavelmente o que se pode traçar como sistema jurídico penal, b) fazem parte do corpo jurídico (jurídico-legislativo, judicial, sua(s) ciência(s) interpretativa(s) correlata(s) e também norma legal que molda e delimita a regularidade de atuação de atores de várias parcelas de tal sistema - ex: atuação policial e procedimentos de execução penal); e, c) são parte de um gerenciamento de governança - policy (Cf. SCHMIDT, 2008) - a respeito de questão pública, a saber, o trato com a questão criminal.

Contudo, é arriscado anuir para com uma teleologia que coliga essa rubrica de função político-criminal do processo (e, por conseguinte, um de seus instrumentos, em comento) a tipos de finalidades que rompem com o cânone substancial de uma visão de processo como filtro garantidor enfraquecida e mais perfilada com fins político-criminais aqui entendidos como punitivos. Dito de outro modo: pode vir a se tornar bastante problemático falar em uma integração político-criminal de ordem teleológica para com o processo penal e seus instrumentos, uma vez que isso arremessaria uma dita finalidade dos processos/ procedimentos penais para o mesmo rumo/vetor do poder punitivo e do espectro de normas penais, campos igualmente (na toada em que estamos tratando o tema) de pertinência de ordem política, mas que são vistos usualmente em uma versão menos alargada de discussão político-criminal. Ou, ainda: vistos usualmente como emblemas de uma visão político-criminal que é menos pautada na discussão do caráter de policies e mais calcada na ideia de que as ramificações do sistema são braços chancelares da aplicação do Direito Penal.

Se não se pautar por chaves de leitura (ou também por chaves de leitura) que variam da necessária índole tensionada constitucionalmente para o processo e suas diretrizes, quanto, mesmo de uma visão 
criminológica como esclarecimento (inclusive politicamente pautado Cf. ALBRECHT, 2010), a consideração teleológica do processo penal pode desaguar em constatações perigosas.

Dessa maneira, não nos parece haver qualquer óbice processual ou político-criminal para que se busque a implementação e adoção de medidas processuais e procedimentais que visem resultados práticos - e aqui o artigo analisado em nosso sentir acerta, em muito, ao escapar da discussão solipsista e um tanto falaciosa que faz a crítica de instrumentos e práticas consensuais em meio ao processo penal sob o ponto de vista estranho de uma 'ética' a ser 'respeitada' entre os réus ou entre os investigados. A discussão dos termos da voluntariedade ou consensualidade presentes, por exemplo, na colaboração tal e qual vai prevista na Lei n. 12.850/2013 precisa ganhar os aportes que os autores fornecem (discussão sobre o caráter de premiação e consenso que gravitam sobre a cooperação na forma de colaboração), e precisam ser estudados diante das condições legítimas para que se ofereçam, em medidas justas, recompensas e deveres (inclusive com a abdicação do máximo efeito de alguns direitos e fatores de gigantesca importância, como são o direito ao silêncio - grafia usual do gênero nemo tenetur - e a própria necessidade de assumir/confessar culpa em certa medida). Os autores não perdem tempo investigando a ideia bastante enviesada de discussão que não raramente se promove em razão do tema, onde a possibilidade de uma colaboração negocial visando (e dificilmente seria diferente) alguma vantagem vai combatida com uma série de bravatas que impõem uma espécie de lealdade jurídica e moral do acusado/suspeito frente a seus pares na suposta ação delituosa. No campo ético pode haver questionamento pessoal sobre isso, mas no campo jurídico, parece que não.

No entanto, o alerta soa quando se insinua o tema em questão como passível de servir de ferramenta teleológica (um problema) para uma visão político-criminal que por vezes se refere ao uso da maquinaria processual puro e simples (outro problema, subsequente e mais agudo).

\section{A DICOTOMIA ENTRE EFICIÊNCIA E GARANTIA EM BREVES APORTES}

O artigo - e aqui há, ou se aproxima de haver, um ponto de divergência bastante sensível que orienta essa crítica científica - refe- 
re uma tensão entre eficientismo e garantismo no domínio da teleologia político-criminal do processo penal: uma tensão que ganha ares de tendência a embasar ou justificar a premissa teleológica pelos autores predileta. A nós, parece que um genuíno garantismo (e aqui se traduz menos como adjetivo ferrajoliano e mais como constatação democrático-constitucional relativa ao ordenamento brasileiro) se coaduna com principiologia constitucional adotada e como filtro e fiscal da profusão do poder punitivo, não necessariamente como barreira monolítica ou vetor oposto ao mesmo. Nessa linha, a necessidade de constatação de que o conteúdo prático e teórico do processo penal seja imantado pela ideia de que há uma postura a ser cobrada constitucionalmente, e ela diz respeito à eleição de uma série de premissas e valores democráticos e de cunho classicamente limitador surge imponente em opinião de literatura de várias matizes disciplinares e ideológicas (Cf. PRADO, 2006, p. 16, FELDENS, 2008 p. 22; SARLET, 2004, p. 142-143), e busca ancoragem nas grandes declarações e tratados para ondem convergem as diretrizes de direitos humanos em padrões das democracias ocidentais

Assim, por mais que sequer se deva discutir a respeito da legitimidade constitucional-democrática de uma persecução penal bem manejada e mesmo a indubitável presença de mandados positivos de criminalização (e, por conseguinte, de persecução) no bojo da própria carta constitucional (e aqui se faz remissão clara à própria base de autores supracitada), o debate que dá tons de oposição entre eficiência e garantia é de certo modo perigoso, e em algum limite imprudente - em nosso ver os autores em comento se mantem de forma elegante e prudente muito mais próximos do primeiro limite, mas é preciso, em nosso ver, o alerta.

$\mathrm{Na}$ linha em que pondera sobre a cruza indiscriminada dessa fronteira, falando sobre tema visivelmente correlato (o ativismo judicial - que muitas vezes é escopo para o ator processual - sumamente jurisdicional - promover por si só o equilíbrio entre eficiência e garantia), Damaška (2000, p. 255, tradução livre) reforça o alarme:

Se o propósito do processo judicial é levar a cabo a política estatal em casos contingentes, as decisões o legitimam em primeiro lugar enquanto resultados concretos que incorporam. Um procedimento correto é aquele que aumenta a probabilidade - ou maximiza a possibilidade - de alcançar um resultado substantivo 
acertado, mais do que outro que torne efetivas as noções de justiça ou proteja algum valor substantivo colateral. Neste sentido, então, o direito processual do estado interventor segue o direito substantivo tão fielmente como uma sombra.

Situar a oposição entre eficiência e garantia é opção ideológica que por vezes termina galvanizando a garantia como maior e exclusiva rival da eficiência e auxilia na construção de um discurso de que o processo deve pender para o lado de uma política criminal que corrobora a eficiência punitiva e se destacar de sua instrumentalidade. É possível defender uma eficiência tributária de garantias básicas de filtro, bem como garantias que não visam a tornar inoperante a exigência de eficiência e de segurança jurídica.

Nesse ponto, acredita-se que não seria conveniente constatações que equalizem a patente preocupação em relação a uma prestação/tutela jurídica eficazes (enquanto direito fundamental do cidadão) e qualquer tipo de valoração dita pro societate em relação aos instrumentos, procedimentos e mesmo à visão macro do processo penal. No campo da premissa valorativa tanto da judicialização de um caso quanto da análise probatória especificada, só cabe necessariamente uma presunção pro reo. A tutela jurídica eficaz - direito cuja confiança social não pode, de fato, ser quebrada - não se exibe no mesmo plano valorativo: vencida pelos indícios informativos e acusatórios e pelas provas e argumentos processuais posteriores, a presunção de inocência dá lugar à afirmação jurídica da culpa. Substitui-se a presunção (mecanismo de escolha axiológica e pragmática para orientar o tratamento dado ao acusado(a) em situação inicial/anterior e os efeitos que sobre ele podem recair) pela certeza (em seu nível cabível) jurídica pós-processo e procedimento (necessários). Assim, não nos parece possível justificar essa atuação e/ou leitura político-criminal de um instituto ou conceito processual visando à eficiência, se valendo de qualquer resquício de lógica tributária de uma inversão do in dubio constitucionalmente decorrente (pro reo) para aquele que não é constitucionalmente adequado (pro societate).

Do mesmo modo, cabe sempre salientar, seria uma medida anti -eficiência processual e tutelar (e por isso, igualmente ilógica e inconstitucional em último plano) defender que o in dubio pro reo decantado 
da presunção constitucional de inocência fosse também combativo no plano do resultado processual de modo a ser visto como algo que não deve. Em outras palavras: a presunção de inocência pode até se apresentar contrária a um eficientismo quando esse se mascarar e mesclar a uma noção punitivista de atuação jurídico-penal do sistema. Mas, na mesma toada, ela é um critério democrático de trato apriorístico em relação à dúvida jurídica, e não um salvo-conduto ou remédio meritório que coliga a constitucionalidade ou prudência de uma decisão a um só conteúdo ou lado da contenda. Por isso, a discussão em torno dos critérios presunção de inocência, eficiência e necessidade da tutela e notas pro societate engloba um debate que não se focaliza sempre no mesmo plano ou linha de diálogo, e costuma dramatizar ainda mais a questão da discussão - quase sempre fazendo das garantias e seus predicados um espectro que militaria em contrariedade à eficiência.

\section{Conclusão}

Se poderia mais uma vez exultar a ideia e o caráter ousado que o texto em comento procura aclarar - e, fundamentalmente, reiterar que é necessário e que se concorda (rompendo com tradições já caducadas em torno do sentido teórico comum na temática) com a premissa de que podem (e devem) ser possibilitados prognósticos de natureza político criminal na própria estrutura do processo penal (conforme os autores referem expressamente). Nisso, há que se deixar claro, está o maior ganho nuclear do trabalho e é onde a tese exposta periga angariar o maior número de críticas errôneas. O que essa crítica científica procurou salientar é que é preciso e possível (e foi o que se mostrou de fato) a discordância sobre quais os vetores e fatores que podem contribuir e prevalecer para que esse legítimo influxo político em meio ao processo floresça. No entanto, convém deixar claro que estamos de pleno acordo com o texto em a) constatar que as normas e conceitos processuais sofrem esse influxo; b) a ocorrência disso não é perversa, 'impura' ou descabida em se tratando de processo penal; c) a ocorrência disso não macula a ciência processual - e, pelo contrário, lhe hidrata de prognóstico prático que por vezes falta frente à análise científica tradicional. 
Mas é preciso que se diga - em opinião que é pura especulação crítica frente ao texto que vem a lume, que d) o pragmatismo em excesso teleológico (ex: medidas diferenciadas para a dita 'criminalidade grave') pode enevoar a visão político-criminal do processo e seus instrumentos para um utilitarismo baixo e de ocasião; e) o empenho funcionalista em conectar política, estratégias, gestão, objetivos e resultados não pode simplesmente se instalar e sobrepor onde há uma série de valores e padrões em que, alguns, inclusive, são talhados para uma imposição ou contra imposição (ex: eficiência vs. garantia) e, por fim, f) a complementariedade funcional entre o desenrolar do processo e suas possibilidades aplicativas e interpretativas com outros ramos jurídicos (máxime as normas de direito penal e sua axiologia) não podem pressupor um processo político-criminalmente orientado que se transforma em estrutura-fantoche do poder punitivo sob argumentos convincentes.

O rico trabalho ofertado pelos autores não foge - à luz de nossas ponderações (e que podem ser eminentemente especulações particulares) - de uma série de pontos conflitivos, mas, inegavelmente, ajuda a construir e a solidificar um campo de discussão negligenciado perante o interesse que ele deveria inspirar. O debate político-criminal do processo, ou mesmo um debate político-processual, a partir de funcionalismos e de estratégias de gestão e resultados precisa irromper uma barreira dogmática excessivamente tradicionalista e avessa a viragens por vezes necessárias. Eis aqui a inegável contribuição do trabalho - tecnicamente bem fundamentado, independentemente de críticas que possa suscitar: propõe discussão mais do que bem-vinda e uma inspiração sobre o tema que foge à trivialidade reacionária.

\section{REFERÊNCIAS}

AIRES, Murilo T.; FERNANDES, Fernando A. A colaboração premiada como instrumento de política criminal: a compatibilidade do instituto com o ordenamento jurídico brasileiro. Revista Brasileira de Direito Processual Penal, Porto Alegre, vol. 3, n. 1, jan./abr. 2017. https://doi.org/10.22197/rbdpp. v3i1.46 
ALBRECHT, Peter Alexis. Criminologia - Uma Fundamentação Para o Direito Penal. Trad. Juarez Cirino dos Santos. Rio de Janeiro/Curitiba: Lumen Juris/ ICPC, 2010.

CASARA, Rubens R. R.; MELCHIOR, Antônio Pedro. Pedro. Teoria do Processo Penal Brasileiro. Dogmática e Crítica: conceitos fundamentais. Volume I. Rio de Janeiro: Lumen Juris, 2014.

CIRINO DOS SANTOS, Juarez. Política criminal: realidades e ilusões do discurso penal. Discursos Sediciosos. Crime, Direito e Sociedade, Rio de Janeiro, v. 7, n. 12, jul./dez., 2002.

DAMASKA, Mirjan R. Las caras de la justicia y el poder de lo Estado. Análisis comparado del proceso legal. Trad. Andréa Morales Vidal. Santiago: Editorial Jurídica de Chile, 2000.

DIVAN, Gabriel Antinolfi. Poderes Instrutórios do julgador do ponto de vista político-processual: índole e instrumentalidade. Anais do III Congresso Internacional de Ciências Criminais. Porto Alegre: EDIPUCRS, 2012.

DIVAN, Gabriel Antinolfi. Processo Penal e Política Criminal: uma reconfiguração da Justa Causa para a Ação Penal. Porto Alegre: Elegantia Juris, 2015.

FELDENS, Luciano. Direitos Fundamentais e Direito Penal. Porto Alegre: Livraria do Advogado, 2008.

FERNANDES, Fernando. O processo penal como instrumento de política criminal. Coimbra: Almedina, 2001.

PRADO, Geraldo. Sistema Acusatório. A conformidade constitucional das leis processuais penais. 4. ed. Rio de Janeiro: Lumen Juris, 2006.

ROXIN, Claus. Política Criminal e Sistema Jurídico-Penal. Trad. Luís Greco. Rio de Janeiro/São Paulo: Renovar, 2000.

SARLET, Ingo Wolfgang. Constituição e Proporcionalidade: o direito penal e os direitos fundamentais entre proibição de excesso e de insuficiência. Revista Brasileira de Ciências Criminais, São Paulo, n. 47, 2004.

SCHMIDT, João Pedro. Para entender as políticas públicas: aspectos conceituais e metodológicos. In: REIS, Jorge Renato dos; LEAL, Rogério Gesta (org.). Direitos Sociais: desafios contemporâneos e políticas públicas. Tomo 8. Santa Cruz do Sul: EDUNISC, 2008. p. 2310-2311. 
Dados do processo editorial - crítica científica

(http://www.ibraspp.com.br/revista/index.php/RBDPP/about/editorialPolicies)

- Recebido em: 09/02/2017

Equipe editorial envolvida

- Decisão preliminar e verificação de plágio:

- Editor-chefe: 1 (VGV) 12/02/2017

- Retorno rodada de correções 1: 12/02/2017

- Decisão editorial final: 13/02/2017

\section{COMO CITAR ESTE TRABALHO:}

DIVAN, Gabriel A. Crítica científica de "A colaboração premiada como instrumento de política criminal" - Um adendo sobre a necessária visão político-criminal do processo penal. Revista Brasileira de Direito Processual Penal, Porto Alegre, vol. 3, n. 1, p. 417-428, jan./abr. 2017. https://doi.org/10.22197/rbdpp.v3i1.55

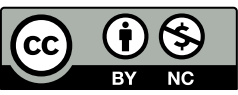

Esta obra está licenciada com uma Licença Creative Commons Atribuição-NãoComercial 4.0 Internacional. 